\title{
LIFE PHASES MODULARISATION OF PRODUCT-SERVICE SYSTEMS
}

\author{
Rennpferdt, Christoph; \\ Krause, Dieter \\ Hamburg University of Technology
}

\begin{abstract}
Product Service Systems (PSS) are increasingly important for companies. They enable a multitude of advantages, including the ability to offer customers even more individual customised solutions. However, PSS can also cause negative effects for companies. For example, PSS increase the complexity within companies. In order to cope with this complexity, the modularisation of PSS is frequently suggested in literature. However, existing approaches for modularisation only consider functional reasons for module composition and neglect the product-strategic aspects. This paper introduces a new approach for the modularisation of PSS, which combines functional and productstrategic aspects into one approach. To achieve this, a separate modular structure is developed for each life phase. Following this, these are harmonised across all life phases. This enables the advantages of the modular PSS structure to be used in all life phases. A PSS family of laser processing machines is used to illustrate the new developed approach.
\end{abstract}

Keywords: Product-Service Systems (PSS), Modularization, Product architecture, Design methods

\section{Contact:}

Rennpferdt, Christoph

Hamburg University of Technology

Institute of Product Development and Mechanical Engineering Design

Germany

christoph.rennpferdt@tuhh.de

Cite this article: Rennpferdt, C., Krause, D. (2021) 'Life Phases Modularisation of Product-Service Systems', in Proceedings of the International Conference on Engineering Design (ICED21), Gothenburg, Sweden, 16-20 August 2021. DOI:10.1017/pds.2021.458 


\section{INTRODUCTION}

A continuous increase in cost pressure and a growing demand for more individualised products leads to the fact that manufacturing firms must diversify their product range (Krause et al., 2014). In order to offer a wider range of products, existing products are expanded to include product-related services, so that companies are changing from pure manufacturers to providers of Product-Service Systems (PSS) (Isaksson et al., 2009). PSS present many advantages for companies, such as strengthening customer loyalty, better differentiation from competitors (Mont, 2002; Isaksson et al., 2009) or an increase of the solution space by combining products and services (Sundin et al., 2009). However, the drawback of PSS is that the overall complexity (Zou et al., 2018) and especially the complexity caused by a high variety (variety-induced complexity) within the company increases (Ezzat et al., 2019; Rennpferdt and Krause, 2020).

Developing modular product structures allow to configure many different (product-) variants based on a few internal company-wide used modules (Krause et al., 2014). This approach is also becoming increasingly important in the context of PSS (Cenamor et al., 2017; Rennpferdt et al., 2019). The literature offers various approaches for the modularisation of PSS, which address different priorities but still need to be improved in terms of complexity (Rennpferdt and Krause, 2020). Hence, this paper presents a novel approach for the modularisation of PSS, which allows the reduction of varietyinduced complexity by considering the requirements of different life phases as well as considering PSS families.

This paper first explains the background for PSS in section 2 and, based on an analysis of existing modularisation methods, the research needs in this field. This is followed by a short description of the developed approach for the Life Phases Modularisation of PSS in section 3. Section 4 then contains a first case study, in which the approach was applied to a PSS family of laser processing machines. The approach and the application are shortly discussed in section 5, before the results are summarised in section 6 and an outlook on further research topics is provided.

\section{BACKGROUND AND RESEARCH NEED}

In the literature, Product-Service Systems (PSS) are defined in different ways. All definitions have in common that they describe PSS in essence as customer-oriented solutions considering both products and services that add value to customers (Goedkoop et al., 1999; Tukker, 2004; Alonso-Rasgado and Thompson, 2006). The proportions of products and services may vary depending on the characteristics of the PSS and the company's business model (Tukker, 2004). Whilst products are material, tangible goods, services are intangible, are produced and consumed simultaneously and can be described as a change of state that represents an economic value (Shostack, 1982; Goedkoop et al., 1999). Due to their different characteristics, products and services have to be treated differently from a product development perspective (Isaksson et al., 2009).

Companies benefit from PSS in many ways, such as increased customer loyalty or the acquisition of new customer group (Alonso-Rasgado and Thompson, 2006; Isaksson et al., 2009). One major disadvantage of PSS is the increasing complexity (Zou et al., 2018), mainly caused by the higher amount of components, their interactions with each other and the increasing variety of product and service components (Rennpferdt and Krause, 2020). In order to address this, the literature refers to the modularisation of PSS (Ezzat et al., 2019; Rennpferdt and Krause, 2020).

The generic procedure of modularisation consists of three steps. First, the existing, hierarchical product structure is split into components. This is followed by the analysis of the components in step two and the subsequent module composition and transfer into a modular product structure in the last step (Krause and Gebhardt, 2018). A module is made up of elements that have stronger links to each other than to elements of other modules (Krause and Gebhardt, 2018). There are various methods in the literature that have been developed for the modularisation of PSS (Larsen et al., 2018; Rennpferdt et al., 2019). As mentioned before, products and services differ in their characteristics. This is a challenge for modularisation, as these differences influence the demands of stakeholders and how the components could be handled. Existing methods for modularisation can be divided into two groups. The methods of the first group emphasise services in the module composition and subordinate product components to service components (Yu et al., 2008; Sakao et al., 2017; Song and Sakao, 2017; Fargnoli et al., 2019)). In contrast to that, methods of the second group simultaneously modularise products and services (Aurich et al., 2006; Wang et al., 2011; Sun et al., 2017; Sheng et al., 2017; Ezzat et al., 2019). Both 
groups share the fact that they form modules mostly on the basis of functional dependencies. For this purpose, often based on the Design Structure Matrix (DSM) (Eppinger and Browning, 2012), dependencies between the components are put into a matrix and then corresponding clusters of modules are formed (Sakao et al., 2017; Ezzat et al., 2019, 2020). The module composition can be supported by various algorithms (Sun et al., 2017; Song and Sakao, 2017; Chen et al., 2020). In contrast to the functional reasons, product strategic reasons for module composition are usually not considered (Rennpferdt et al., 2019), but represent a powerful lever for mastering complexity, especially when an whole product family is modularised (Salvador, 2007). The only exceptions are methods that also take sustainability aspects into account for module composition (Aurich et al., 2006; Sheng et al., 2017).

To reduce the rising complexity referred to before, products, services and the interrelation between them should be considered simultaneously during modularisation. In some approaches, the interactions are already taken into account by functional dependencies (Sun et al., 2017; Fargnoli et al., 2019), but the interactions between product and service components have not been considered yet. However, since this is one of the driving forces of the increasing complexity (Rennpferdt and Krause, 2020), a new approach should take this into consideration. To achieve this, modularisation should also not only be carried out individually for each PSS variant, but instead a modular structure should be developed to cover the entire PSS family and thus also take variety into account.

The transition from product to PSS affects the product life cycle (Isaksson et al., 2009; Matschewsky et al., 2018; Rennpferdt and Krause, 2020). A product life cycle consists of different life phases, an example is shown in Figure 1, that each represent a corporate function along the product development process or usage phase (Krause and Gebhardt, 2018). Behind each life exists a department that aims to implement its requirements on the product structure. In this context, a department is an organisational unit of a company. For product development it is commonly understood that the development of modular product structures affects the entire product life cycle and that different effects occur in each life phase (Hackl et al., 2020). To be able to use these effects in a target-oriented way, it is important to include the requirements from different life phases and the corresponding module requirements in the module development process. When considering PSS, the life phase usage is particularly important. For conventional products, the focus is usually on efficient production, whereas the importance of the life phase usage is increasing, especially for use-oriented and result-oriented PSS (see (Tukker, 2004)). Existing methods address different life phases by taking into account the requirements of the stakeholders from the product life cycle in the functional modularisation. However, they do not include the life-phase specific requirements of the departments on the module structure and processes.

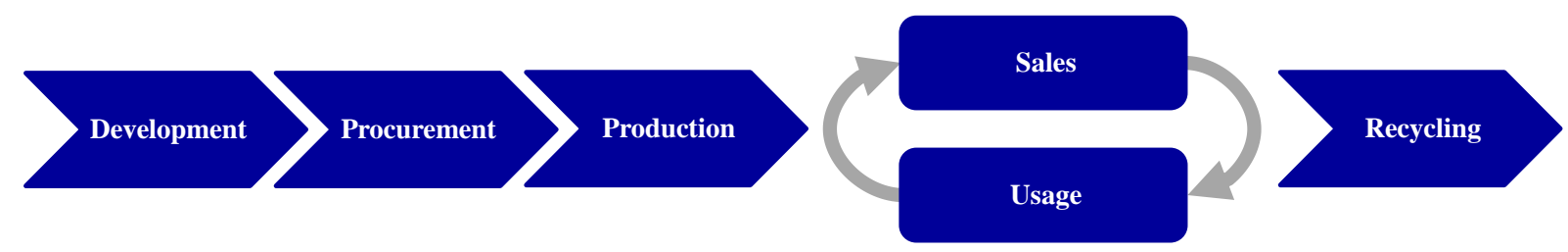

Figure 1: Example for the life phases of a use-oriented product-service system

Summarising, it can be said that there is a need for a method for the modularisation of PSS, which adheres to the requirements of all departments and stakeholders of the product life cycle and their module requirements, takes up functional and product-strategic approaches for modularisation and considers the aspects of variety and variety-induced complexity in module composition.

To address the research needs identified, a new approach for modularisation of PSS is being developed and presented in the next section. The approach is based on the Life Phases Modularisation according to Blees et al. (2010), which has been validated and continuously improved in a number of research projects (Krause et al., 2014; Greve et al., 2020). The Life Phase Modularisation combines technicalfunctional and product-strategic aspects for modularisation and enables the module requirements from different life phases to be included in the development of the module structure. A unique feature of Life Phases Modularisation is the Module Process Chart (MPC), which supports the identification of conflicts and contradictions between the module requirements of the individual life phases (Krause et al., 2014; Greve et al., 2020). So far, however, only tangible products have been modularised. Services or software have not been included. The newly developed approach for the modularisation of PSS, based on Life Phases Modularisation, is introduced in the following. 


\section{APPROACH FOR LIFE PHASES MODULARISATION OF PSS}

In this section, the adapted and enhanced approach is presented. It was developed based on the DRM approach by Blessing and Chakrabarti (2009). Compared to existing methods of PSS modularisation, the major innovation is that not only functional dependencies are considered and e.g. modules are clustered using algorithms, but also product strategic aspects from all life phases are included. The result is a modular structure that is harmonised over the entire PSS life cycle, enabling to configure different variants of PSS from a few internal modules.

Based on the previously mentioned Life Phases Modularisation, the approach presented here is adapted and enhanced accordingly for the modularisation of PSS to meet the research needs described in section 2. The application of the method is still workshop-based, which has the advantage that employees from different departments and life phases jointly develop and coordinate the modular structure. This guarantees that the requirements of the different stakeholders are taken into account and that the acceptance of the solution found increases within the company. The approach to the life phase modularisation of PSS is shown in Figure 2.

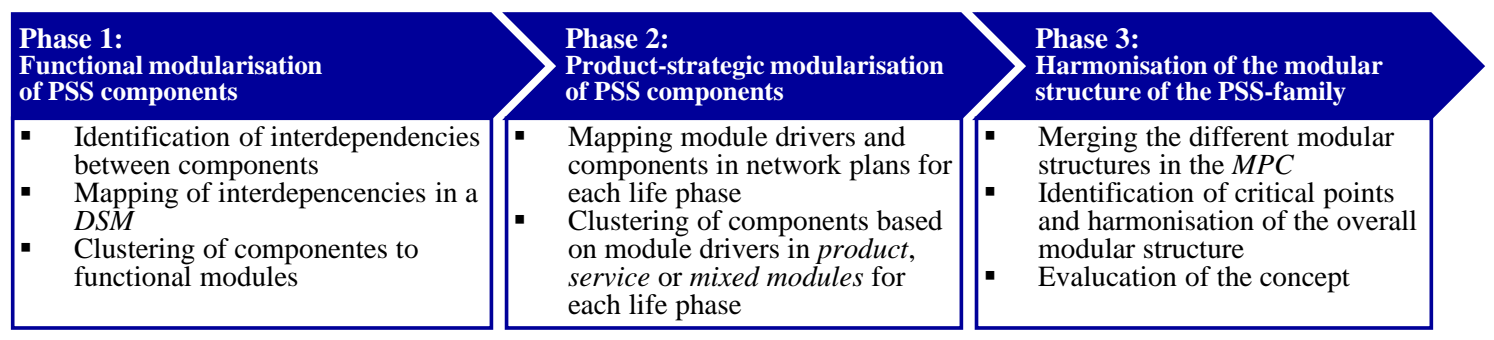

Figure 2: Approach for the Life Phases Modularisation of PSS

During the first phase of the approach, a technical-functional modularisation is carried out. For this, the PSS family, e.g. a product family of printers with corresponding service options, is broken down into product and service components. Examples of product components are sensors, motors or housings, examples of services are software training or condition monitoring. The components are then merged into modules as part of the technical-functional modularisation process. This creates a modular structure based on functional dependencies. The second phase involves developing a life phase-specific modular structure for each PSS life phase (see Figure 1). In this the concept of module drivers is used and extended by PSS-specific module drivers. In the third phase of the approach, the individual modular structures of the life phases are summarised and harmonised in the Module Process Chart (MPC). The result is a continuous modular structure which can be used as a starting point for the configuration of a wide range of products. As a result of modularisation, internal variety becomes more manageable and the complexity within the company decreases.

In the following detailed description of the phases, the focus is on the PSS-specific adaptations.

\subsection{Phase 1: Technical-functional modularisation of the PSS}

For complex systems such as a PSS, the functionalities to meet customer demands have top priority. Therefore, the first phase of the approach is to develop the technical-functional modular structure. First this involves analysing the interactions between the product and service components. The objective of this is to understand the functional dependencies of the PSS family.

In order to obtain a modular structure, the use of a DSM is proposed, which clusters the components into modules based on the functional dependencies. Alternatively, the use of other functional approaches from section 2 would be conceivable. Three different types of modules can be created by clustering:

- Product modules: consist only of tangible components, e.g. mechanical, electronic and software parts

- Service modules: consist of service-related components, e.g. service processes, service resources

- Mixed modules: consist of both product-related and service-related components

The result of the first phase is a modular structure from technical-functional point of view.

\subsection{Phase 2: Product-strategic modularisation of the PSS}

It is well known that product modularisation has different outcomes and impacts in each life phase (Hackl et al., 2020). For this reason, there is not one modular structure that fits all life phases, but 
rather a different optimum for each product life phase. This can also be applied to services or PSS. Consequently, in the second phase of the approach, a separate modular structure is developed for each life phase. Network plans are used to support this, which are developed with experts from the respective life phases. The network plans take up the concept of module drivers and module driver specifications presented by Erixon (1998) and are further developed for Life Phases Modularisation. Regarding PSS, new module drivers specific to services and PSS are developed, e.g. same processes, same resource, consulting, monitoring, same domain.

For which life phases the network plans should be created depends on various factors, such as the type of PSS, the industry or the business model. Figure 3 shows an example of a network plan. Starting from the left, the module drivers are connected to the PSS components via the module driver specifications. In the next step, the modules are composed based on the linking of module driver specifications and components. If there are conflicting assignments (see product component $\mathrm{B}$ ), the module driver specifications must be weighed against each other and a decision must be made. As in the previous phase, three different types of modules can be created. The functional modules developed in the previous phase can be used as the basis for module development in the life phase development. To support the creation of the modules in the network plans, three recommendations are presented:

- Product modules should be formed in such a way that they consist of standard components wherever possible. Since changes to product-related components are usually more expensive than changes to services, the product modules should be standardised as much as possible. In this way, modification efforts can be reduced and economies of scale can be used.

- The modular structure in the service modules in the MPC should be kept as fragmented as possible in order to be able to configure the greatest possible variety of offers by combining the different services.

- The modular structure at the level of the PSS modules should be set up in such a way that a module always covers a customer-relevant property, in order to keep the number of required module variants low. In this way the variety and the variety-induced complexity caused by this can be kept low.

The result of this phase are the life-phase specific modular structures.

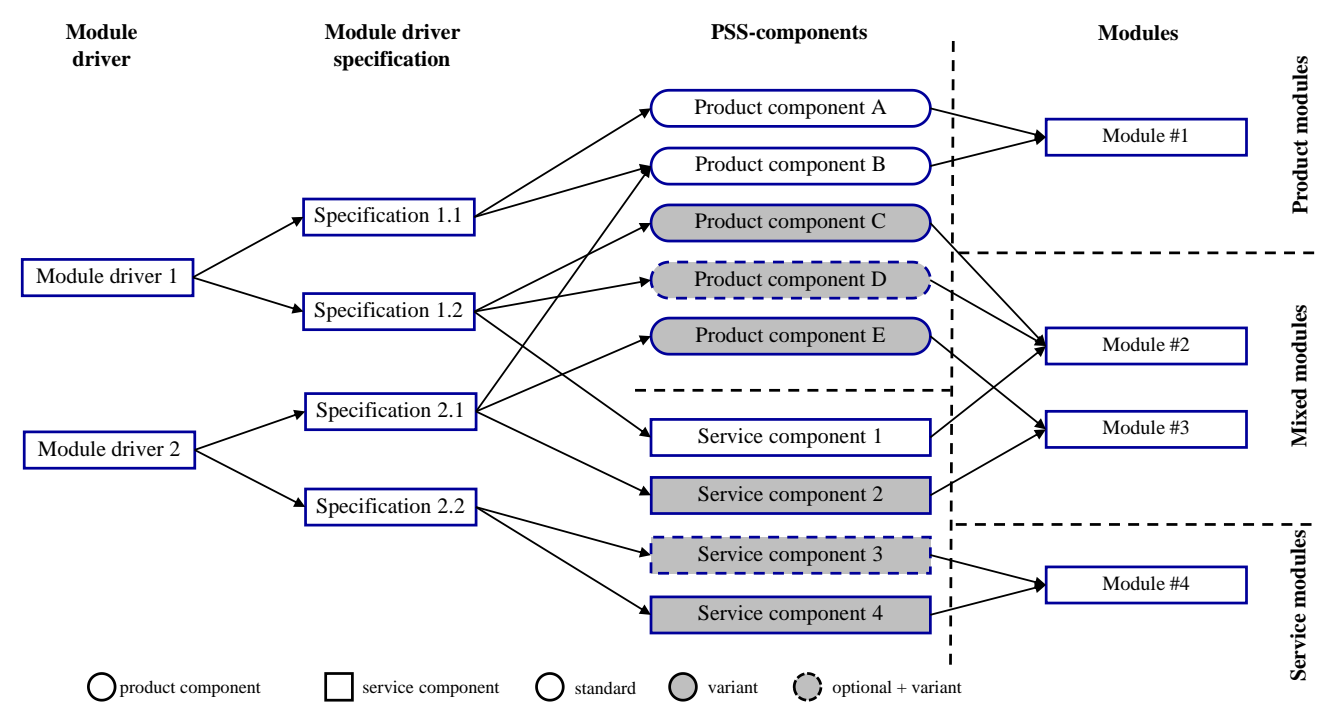

Figure 3: Example for a network plan with different types of modules

\subsection{Phase 3: Harmonisation of the PSS}

In the third phase, the previously developed modular structures are harmonised into a consistent concept. The MPC shown in Figure 4 is used as a tool for this. The sequence of the life phases can vary depending on the PSS and the business model. As PSS are usually designed for a long life cycle, individual life phases may also be repeated. This occurs when a product is leased to another customer after use. In such case, the life phases of usage and sales up to recycling would be repeated several times. After merging the individual modular structures, possible points of conflict are identified and discussed. The objective of this is to harmonise the modular structures of the individual life phases. Ideally, the modules should become larger until usage in order to simplify work content. If modules 
are split up into small modules again, the associated documents, for example, cannot be continued but have to be split as well, which causes additional work and thus costs. In case of conflicts between life phases, the life phases in which the main value creation takes place should be decisive. Which phase it is depends on the company's business model and the type of PSS. In the case of result-based PSS, this would be e.g. the sales and usage phase, in which the modular structure is set up in such a way that various options can be added and maintenance and repairs can be done at low cost.

In the last step of the phase, the developed overall concept is evaluated and then further elaborated.

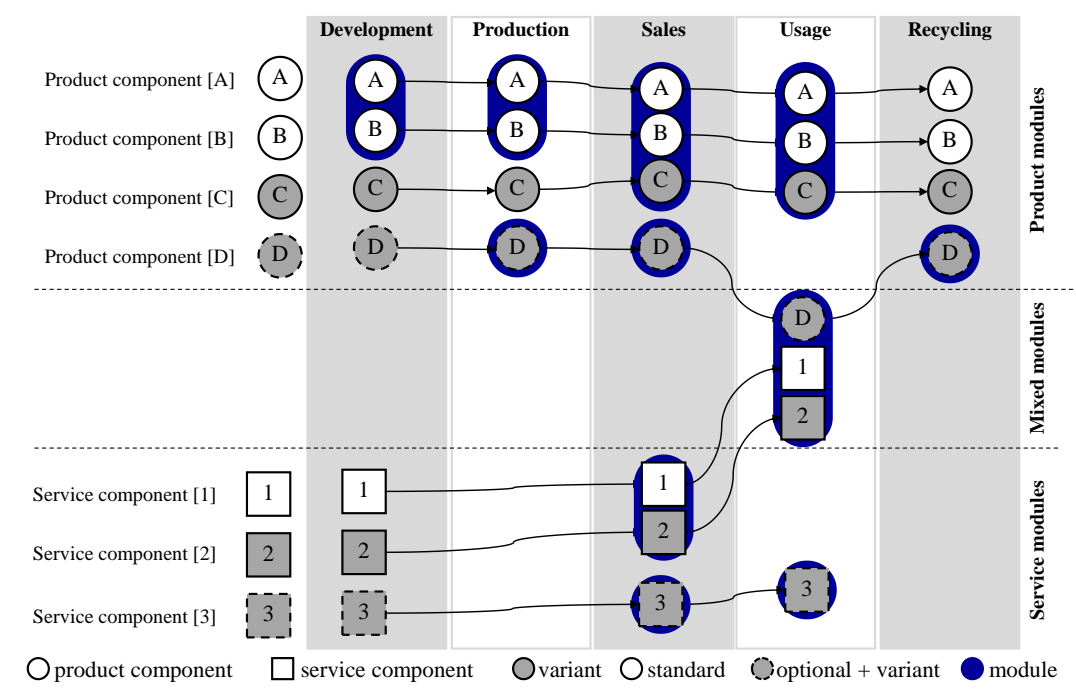

Figure 4: Enhanced Module Process Chart for PSS harmonisation

\section{APPLICATION OF THE PROPOSED APPROACH}

The developed approach for modularisation of PSS is applied in this section to a PSS family of laser processing machines (see Figure 5). Company data was used for the application and the results were discussed with the head of research and development. Within the scope of the application example, a modular concept for the PSS family needed to be developed, which includes process monitoring and optimisation as well as various maintenance options within the framework of a pay-per-use business model.

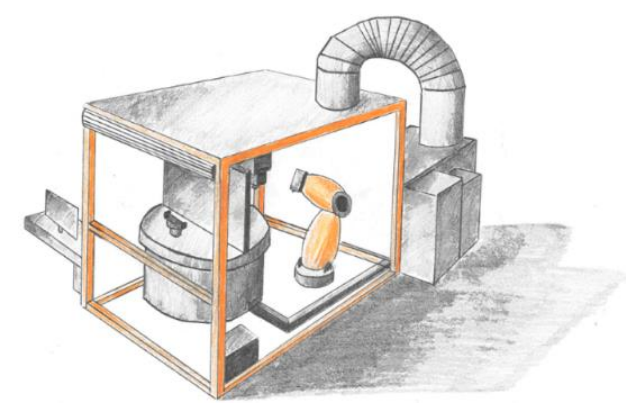

Figure 5: Schematic representation of the application example laser processing machine

Due the scope of this publication, only the main findings of the method application are shown below. After the decomposition and analysis of the existing product and service structures, a functional modularisation of the laser machines was carried out according to phase 1 of the approach. In the next phase, the network plans were developed. Figure 6 shows an extract of the network plan for the life phase development. Figure 6 shows that there is a large number of module drivers and module driver specifications that are linked to the components and that this results in contradictory options for module composition. The modular structure shown on the right was developed using the technicalfunctional modules from phase 1 and the presented recommendations. For instance, the safety module (see 1 in Figure 6) was divided into two smaller modules in order to obtain a standard module (Safety module I). Thus this can be produced in higher quantities, and reduce costs and complexity. From a development point of view, several standard modules could be created for the mixed modules as well. 


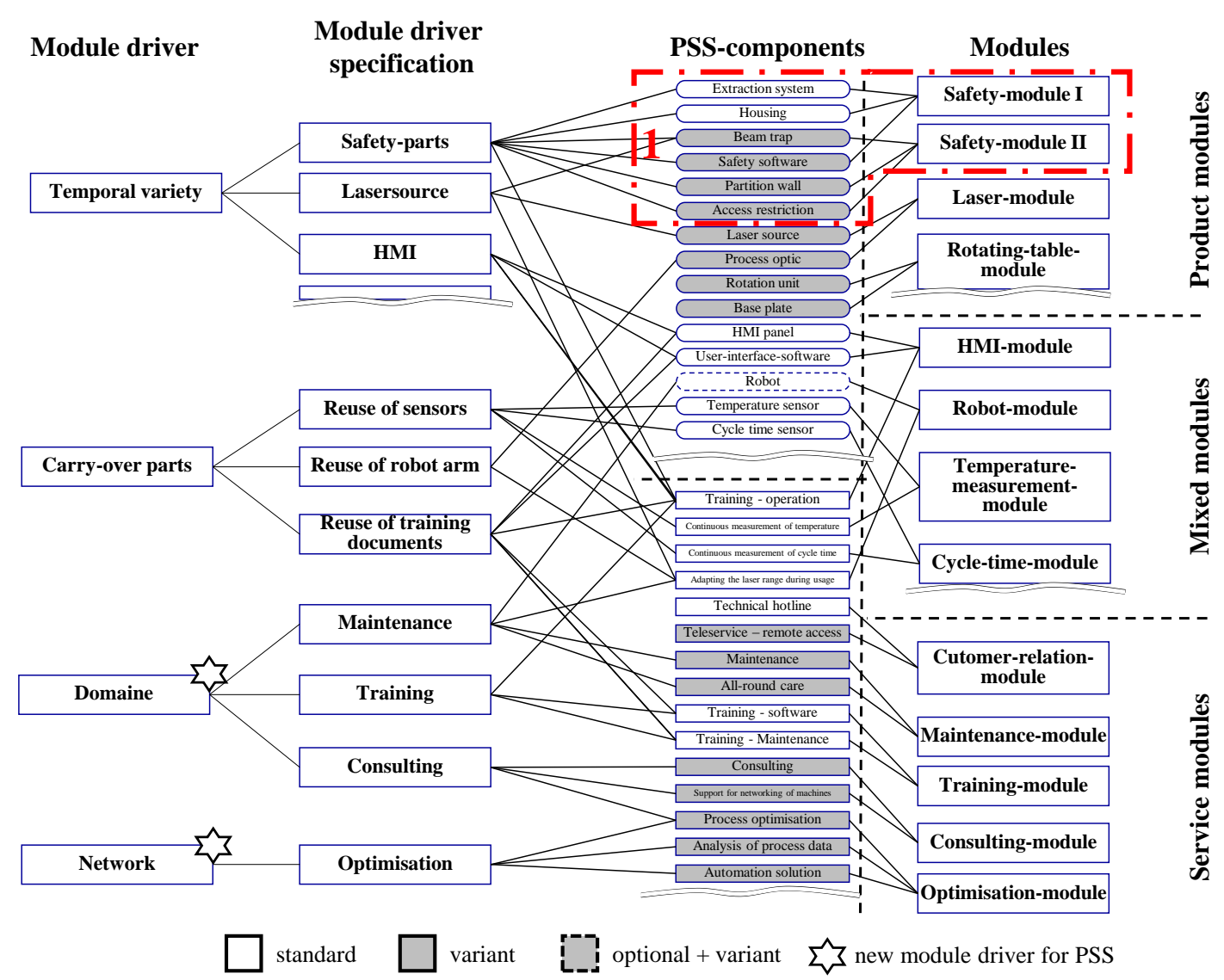

Figure 6: Extract of the network plan for the life phase development

In the third phase of the approach, the harmonisation of the individual module structure concepts was carried out. For the considered laser processing machine, a long service life of $>20$ years is planned, whereas the components to be produced with the machine for the automotive industry change every 5 years at the latest. Therefore, the PSS module concept should be structured in a way that existing machines can be regularly adapted to customer requirements. For this reason, the life phases in the MPC will return to sales after usage. Figure 7 shows the MPC after harmonisation. Prior to harmonisation there were points of conflict mainly due to contradictory module assignments between the life phases development, procurement and production and during the transition from the usage phase to sales. In production, three standard modules were defined which can be produced in high volumes and thus enable economies of scale (see 1 in Figure 7). In usage, two product modules were created, of which the module containing the housing is standard and thus forms a platform (see 2 in Figure 7). A detailed modular structure in the services allows the machine to be adapted to changing customer requirements (see 3 in Figure 7). Due to the harmonised modular structure, defined interfaces between the modules and between life phases could be established, reducing the complexity within the company. Moreover, the small-scale modular structure of the services enables the PSS to be easily adapted to individual customer requirements.

\section{DIScussion}

Applying the approach to an industrial example and the discussion with a company representative afterwards has shown that it is suitable for the modularisation of PSS. The developed concept of the modular PSS structure enables utilising the advantages of modularisation in every life phase, for example by allowing parallel work on the different modules in development, or on the flexible service modules in the usage phase. The modular structure can be set up in such a way that the product modules have as little variety as possible and can therefore be produced in larger quantities. The services, which can be adapted much more flexibly to customer requirements due to their characteristics, are used for the differentiation of the PSS variants. Especially due to the increasing batch sizes of the product modules, it is possible to reduce costs and, and complexity by using defined interfaces between modules in all life phases. 


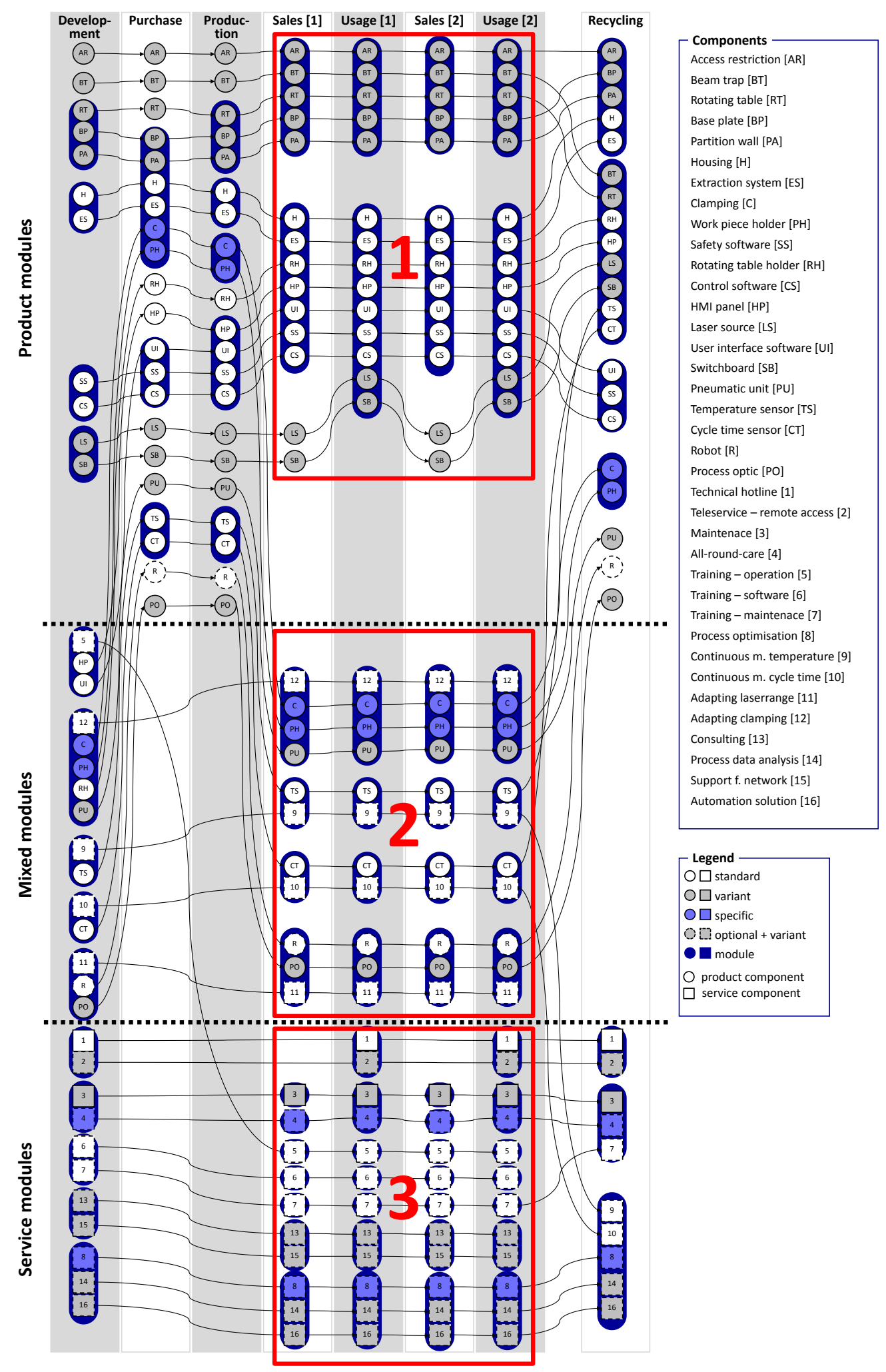

Figure 7: Module Process Chart (MPC) of the PSS after the harmonisation

A criticism of the approach shown is that it focusses on the revision of existing PSS. In the case of a new development of PSS, e.g. when existing products are complemented by new services, a lack of experience with the PSS may result in creating modular structures that do not correspond to the optimal structure of the company.

It should also be noted that although modularisation reduces complexity, this effect could still be increased by upstream optimisation of the variety. This could be achieved by adding a further method step (see (Rennpferdt and Krause, 2020)) and, for example, by outsourcing PSS variety in software components (Rennpferdt and Krause, 2019). 


\section{CONCLUSION AND OUTLOOK}

This paper identified a need for research based on an analysis of existing methods for the modularisation of PSS. Subsequently, an approach was developed and presented to cover this demand. The presented approach consists of three phases, on which the first phase is a functional modularisation. Following this, a separate modular structure is developed for each PSS life phase. The modular structure is developed on the basis of life-phase specific module drivers and documented in network plans. These differentiate between three different types of modules: product, service and mixed modules. The individual modular structures are then harmonised into an overall concept in the third phase of the approach. Here, an attempt is made to set up the modular structure in such a way that it can be adapted very flexibly during the usage phase. Module composition in phases two and three is supported by PSS-specific recommendations.

Subsequently the developed approach was applied to an industrial example in which a modular structure was developed for a PSS family of laser processing machines and discussed.

In future work the approach should be applied to further examples, e.g. for different PSS-types and in different industries. Furthermore, additional PSS-specific module drivers should be determined and include the required resources for services could be included. In addition, the option of a model-based realisation of the approach should be examined in order to be able to modularise large PSS in a verifiable way and to enable automated allocation of components to module types.

\section{REFERENCES}

Alonso-Rasgado, T. and Thompson, G. (2006), “A rapid design process for Total Care Product creation”, Journal of Engineering Design, Vol. 17 No. 6, pp. 509-531. http://dx.doi.org/10.1080/09544820600750579

Aurich, J.C., Fuchs, C. and Wagenknecht, C. (2006), "Life cycle oriented design of technical Product-Service Systems", Journal of Cleaner Production, Vol. 14 No. 17, pp. 1480-1494. http://dx.doi.org/10.1016/j.jclepro.2006.01.019

Blees, C., Jonas, H. and Krause, D. (2010), "Development of Modular Product Families", in Wynn, D.C., Kreimeyer, M., Eben, K., Maurer, M., Lindemann, U. and Clarkson, J. (Eds.), Managing complexity by modelling dependencies: Proceedings of the 12th International DSM Conference Cambridge, UK, 22 - 23 July 2010, Cambridge, 22.-23.07.2010, Hanser, München, pp. 169-182

Blessing, L.T. and Chakrabarti, A. (2009), DRM, a Design Research Methodology, Springer London, London. http://dx.doi.org/10.1007/978-1-84882-587-1

Cenamor, J., Rönnberg Sjödin, D. and Parida, V. (2017), “Adopting a platform approach in servitization: Leveraging the value of digitalization", International Journal of Production Economics, Vol. 192, pp. 54-65. http://dx.doi.org/10.1016/j.ijpe.2016.12.033

Chen, Z., Ming, X., Vareilles, E. and Battaia, O. (2020), "Modularization of smart product service: A framework integrating smart product service blueprint and weighted complex network", Computers in Industry, Vol. 123, p. 103302. http://dx.doi.org/10.1016/j.compind.2020.103302

Eppinger, S.D. and Browning, T.R. (2012), Design structure matrix methods and applications, Engineering systems, MIT Press, Cambridge, Mass.

Erixon, G. (1998), "Modular Function Deployment - A method for product modularization”, PhD Thesis, The Royal Institute of Technology, Stockholm, Sweden, 1998

Ezzat, O., Medini, K., Boucher, X. and Delorme, X. (2019), "Product and service modularization for variety management", Procedia Manufacturing, Vol. 28, pp. 148-153. http://dx.doi.org/10.1016/j.promfg.2018.12.024

Ezzat, O., Medini, K., Boucher, X. and Delorme, X. (2020), “A clustering approach for modularizing serviceoriented systems", Journal of Intelligent Manufacturing. http://dx.doi.org/10.1007/s10845-020-01668-w

Fargnoli, M., Haber, N. and Sakao, T. (2019), "PSS modularisation: a customer-driven integrated approach", International Journal of Production Research, Vol. 57 No. 13, pp. 4061-4077. http://dx.doi.org/10.1080/00207543.2018.1481302

Goedkoop, M.J., van Halen, C.J., Te Riele, H.R. and Rommens, P.J. (1999), "Product Service systems, Ecological and Economic Basics", Report for Dutch Ministries of environment (VROM) and economic affairs (EZ), Vol. 36 No. 1 , pp. $1-122$

Greve, E., Rennpferdt, C. and Krause, D. (2020), "Harmonizing cross-departmental Perspectives on Modular Product Families", Procedia CIRP, Vol. 91, pp. 452-457. http://dx.doi.org/10.1016/j.procir.2020.02.198

Hackl, J., Krause, D., Otto, K., Windheim, M., Moon, S.K., Bursac, N. and Lachmayer, R. (2020), "Impact of Modularity Decisions on a Firm's Economic Objectives”, Journal of Mechanical Design, Vol. 142 No. 4. http://dx.doi.org/10.1115/1.4044914 
Isaksson, O., Larsson, T.C. and Rönnbäck, A.Ö. (2009), "Development of product-service systems: challenges and opportunities for the manufacturing firm", Journal of Engineering Design, Vol. 20 No. 4, pp. 329-348. http://dx.doi.org/10.1080/09544820903152663

Krause, D., Beckmann, G., Eilmus, S., Gebhardt, N., Jonas, H. and Rettberg, R. (2014), "Integrated Development of Modular Product Families: A Methods Toolkit”, in Simpson, T.W., Jiao, J., Siddique, Z. and Hölttä-Otto, K. (Eds.), Advances in Product Family and Product Platform Design: Methods \& applications, Advances in Product Family and Product Platform Design, Springer New York, New York, NY, pp. 245-269. http://dx.doi.org/10.1007/978-1-4614-7937-6_10

Krause, D. and Gebhardt, N. (2018), Methodische Entwicklung modularer Produktfamilien, Springer Berlin Heidelberg, Berlin, Heidelberg. http://dx.doi.org/10.1007/978-3-662-53040-5

Larsen, M.S.S., Andersen, A.-L., Nielsen, K. and Brunoe, T.D. (2018), "Modularity in Product-Service Systems: Literature Review and Future Research Directions”, in Moon, I., Lee, G.M., Park, J., Kiritsis, D. and von Cieminski, G. (Eds.), Advances in Production Management Systems. Production Management for DataDriven, Intelligent, Collaborative, and Sustainable Manufacturing, Vol. 535, Springer International Publishing, Cham, pp. 150-158. http://dx.doi.org/10.1007/978-3-319-99704-9_19

Matschewsky, J., Kambanou, M.L. and Sakao, T. (2018), "Designing and providing integrated product-service systems - challenges, opportunities and solutions resulting from prescriptive approaches in two industrial companies”, International Journal of Production Research, Vol. 56 No. 6, pp. 2150-2168. http://dx.doi.org/10.1080/00207543.2017.1332792

Mont, O. (2002), "Clarifying the concept of product-service system”, Journal of Cleaner Production, Vol. 10 No. 3, pp. 237-245. http://dx.doi.org/10.1016/S0959-6526(01)00039-7

Rennpferdt, C. and Krause, D. (2019), “Adapted Design for Variety: Consideration of the Software-Domain”, in 2019 IEEE International Conference on Industrial Engineering and Engineering Management: IEEM2019 15-18 Dec, Macau, Macao, IEEE, pp. 950-954. http://dx.doi.org/10.1109/IEEM44572.2019.8978493

Rennpferdt, C., Greve, E. and Krause, D. (2019), “The Impact of Modular Product Architectures in PSS Design: A systematic Literature Review", Procedia CIRP, Vol. 84, pp. 290-295. http://dx.doi.org/10.1016/j.procir.2019.04.197

Rennpferdt, C. and Krause, D. (2020), "Towards a Framework for the Design of Variety-Oriented Product-Service Systems", Proceedings of the Design Society: DESIGN Conference, Vol. 1, pp. 1345-1354. http://dx.doi.org/10.1017/dsd.2020.108

Sakao, T., Song, W. and Matschewsky, J. (2017), "Creating service modules for customising product/service systems by extending DSM”, CIRP Annals, Vol. 66 No. 1, pp. 21-24. http://dx.doi.org/10.1016/j.cirp.2017.04.107

Salvador, F. (2007), “Toward a Product System Modularity Construct: Literature Review and Reconceptualization”, IEEE Transactions on Engineering Management, Vol. 54 No. 2, pp. 219-240. http://dx.doi.org/10.1109/TEM.2007.893996

Sheng, Z., Liu, C., Song, J. and Xie, H. (2017), "Module division and configuration modeling of CNC productservice system", Proceedings of the Institution of Mechanical Engineers, Part C: Journal of Mechanical Engineering Science, Vol. 231 No. 3, pp. 494-506. http://dx.doi.org/10.1177/0954406215616424

Shostack, G.L. (1982), "How to Design a Service”, European Journal of Marketing, Vol. 16 No. 1, pp. 49-63. http://dx.doi.org/10.1108/EUM0000000004799

Song, W. and Sakao, T. (2017), “A customization-oriented framework for design of sustainable product/service system", Journal of Cleaner Production, Vol. 140, pp. 1672-1685. http://dx.doi.org/10.1016/j.jclepro.2016.09.111

Sundin, E., Lindahl, M., Comstock, M., Sakao, T. and Shimomura, Y. (2009), “Achieving mass customisation through servicification”, International Journal of Internet Manufacturing and Services, Vol. 2 No. 1, p. 56. http://dx.doi.org/10.1504/IJIMS.2009.031340

Sun, J., Chai, N., Pi, G., Zhang, Z. and Fan, B. (2017), "Modularization of Product Service System Based on Functional Requirement", Procedia CIRP, Vol. 64, pp. 301-305. http://dx.doi.org/10.1016/j.procir.2017.03.038

Tukker, A. (2004), "Eight types of product-service system: eight ways to sustainability? Experiences from SusProNet”, Business Strategy and the Environment, Vol. 13 No. 4, pp. 246-260. http://dx.doi.org/10.1002/bse.414

Wang, P.P., Ming, X.G., Li, D., Kong, F.B., Wang, L. and Wu, Z.Y. (2011), "Modular Development of Product Service Systems", Concurrent Engineering, Vol. 19 No. 1, pp. 85-96. http://dx.doi.org/10.1177/1063293X11403508

Yu, M., Zhang, W. and Meier, H. (2008), "Modularization based design for innovative product-related industrial service", in Proceedings of 2008 IEEE International Conference on Service Operations and Logistics, and Informatics, IEEE SOLI 2008: October 12 - 15, 2008, Beijing, China, Beijing, China, 12.10.2008 15.10.2008, IEEE, Piscataway, NJ, pp. 48-53. http://dx.doi.org/10.1109/SOLI.2008.4686360

Zou, W., Brax, S.A. and Rajala, R. (2018), "Complexity in Product-Service Systems: Review and Framework", Procedia CIRP, Vol. 73, pp. 3-8. http://dx.doi.org/10.1016/j.procir.2018.03.319 